\title{
The genetic basis for inherited forms of sinoatrial dysfunction and atrioventricular node dysfunction
}

\author{
Raffaella Milanesi $^{1,2}$ - Annalisa Bucchi ${ }^{1,2} \cdot$ Mirko Baruscotti $^{1,2}$ \\ Received: 11 November 2014 / Accepted: 13 March 2015 /Published online: 12 April 2015 \\ (C) The Author(s) 2015. This article is published with open access at Springerlink.com
}

\begin{abstract}
The sinoatrial node (SAN) and the atrioventricular node $(\mathrm{AVN})$ are the anatomical and functional regions of the heart which play critical roles in the generation and conduction of the electrical impulse. Their functions are ensured by peculiar structural cytological properties and specific collections of ion channels. Impairment of SAN and AVN activity is generally acquired,but in some cases familial inheritance has been established and therefore a genetic cause is involved. In recent years, combined efforts of clinical practice and experimental basic science studies have identified and characterized several causative gene mutations associated with the nodal syndromes. Channelopathies, i.e., diseases associated with defective ion channels, remain the major cause of genetically determined nodal arrhythmias; however, it is becoming increasingly evident that mutations in other classes of regulatory and structural proteins also have profound pathophysiological roles. In this review, we will present some aspects of the genetic identification of the molecular mechanism underlying both SAN and AVN dysfunctions with a particular focus on mutations of the $\mathrm{Na}$, pacemaker ( $\mathrm{HCN})$, and $\mathrm{Ca}$ channels. Genetic defects in regulatory proteins and calcium-handling proteins will be also considered. In conclusion, the identification of the genetic defects associated with familial nodal dysfunction is an essential step for implementing an appropriate therapeutic treatment.
\end{abstract}

Mirko Baruscotti

mirko.baruscotti@unimi.it

1 Department of Biosciences, University of Milano, via Celoria 26, 20133 Milan, Italy

2 Centro Interuniversitario di Medicina Molecolare e Biofisica Applicata, University of Milano, Milan, Italy
Keywords SAN $\cdot$ AVN $\cdot$ Sick sinus syndrome .

Atrioventricular block $\cdot$ SAN dysfunction $\cdot$ AVN dysfunction

\section{Introduction}

The sinoatrial node (SAN) and the atrioventricular node (AVN), together with the His-Purkinje fibers, form the cardiac conduction system (CCS). The SAN is the primary rhythm generator of the heart due to the spontaneous electrical activity of its pacemaker cells, while the AVN ensures, after imposing an appropriate frequency-dependent delay, the propagation of the impulse from the atria to the ventricles. At a mature stage, the cells of the CCS, and particularly those of the SAN and $\mathrm{AVN}$, have significant cytological and functional differences when compared to those of the working myocardium: the nodal cells are smaller, have a less-defined sarcomeric organization, and a lower cell-to-cell electrical coupling [1]. Moreover, nodal cells spontaneously generate action potentials due to a specific set of ion channels [2]. Any alteration of the delicate balance between the structural organization and the electrical profile of these cells can thus lead to dysfunctions of impulse generation and conduction. SAN and AVN dysfunctions include a large number of pathological conditions: in most cases they are acquired; but in some cases, they are inherited, and therefore a genetic cause is involved $[1,3-6]$. Genetic transmission of a disease is said to be monogenic when the defect is localized in a single gene and to be multigenic when the mutations are present in two or more genes. Despite this simple distinction, there is ample evidence that the phenotypic expression of gene defects is highly complex since incomplete penetrance and high variability are often present. Incomplete penetrance, for example, occurs when an autosomal dominant monogenic disease trait is present in genetically related siblings and only some of them are 
clinically affected. The presence of variability instead indicates that affected individuals may present a large phenotypic heterogeneity that spans from mild to severe symptoms.

Genetic diseases are commonly thought to have an early onset in life, but this concept does not always hold true since physiological age-dependent molecular and structural remodeling of a given tissue/organ may magnify the pathological impact of a defective gene in the adult or in the elderly. In this regard, it should be considered that the SAN is composed of a relatively low number of cells, and it is known to undergo substantial structural and electrical modifications during ageing, with a reduction in the nodal area and possibly with an increase of fibrotic tissue [1]. Thus, it is conceivable that these structural and electrical age-dependent modifications could in principle set the stage for the late onset of genetic diseases which are not present in young individuals.

The identification of defective genes causing SAN and AVN dysfunctions is starting to emerge from multiple approaches such as genome-wide association studies, the candidate gene approach, and the whole-genome or whole-exome next-generation sequencing. In addition to these genetic studies carried out on humans, a source of valuable information comes from the use of transgenic animal models.

\section{Anatomy and physiology of the sinoatrial and atrioventricular nodes}

The SAN is located in the posterior wall of the right atrium, in the intercaval region adjacent to the atrial muscle of the crista terminalis, extending from the superior to near the inferior vena cava, and is organized as a mesh-like structure of sparsely organized myocytes embedded in a dense supporting connective matrix [1, 7] (Fig. 1a). The cellular architecture of the SAN is not uniform since, moving from the center to the periphery, there is a smooth transition from smaller primary pacemaker cells to cells that progressively assume more atriallike features [1]. Highly specialized central SAN myocytes generate rhythmic pacemaker action potentials that are then orderly conveyed to the rest of the myocardium. It is worth mentioning that when rates are evaluated at the single-cell level, cells from the periphery of the node beat faster than those from the center of the node; however, in in vivo conditions, the cells from the periphery have a slower rate due to the hyperpolarizing influence of the surrounding atrial tissue [8].

The main feature of SAN cell autorhythmicity is the presence between consecutive action potentials of a slow diastolic depolarization (pacemaker phase) which sets the cardiac rate. Among the molecular mechanisms that are at work to support this phase, primary roles are played by the pacemaker $\mathrm{f}$ channels (membrane clock) [2,9] and by intracellular $\mathrm{Ca}^{2+}$ release $\left(\mathrm{Ca}^{2+}\right.$-clock) [10]. Molecular studies have shown that specific patterns of mRNA/protein expression can be used as
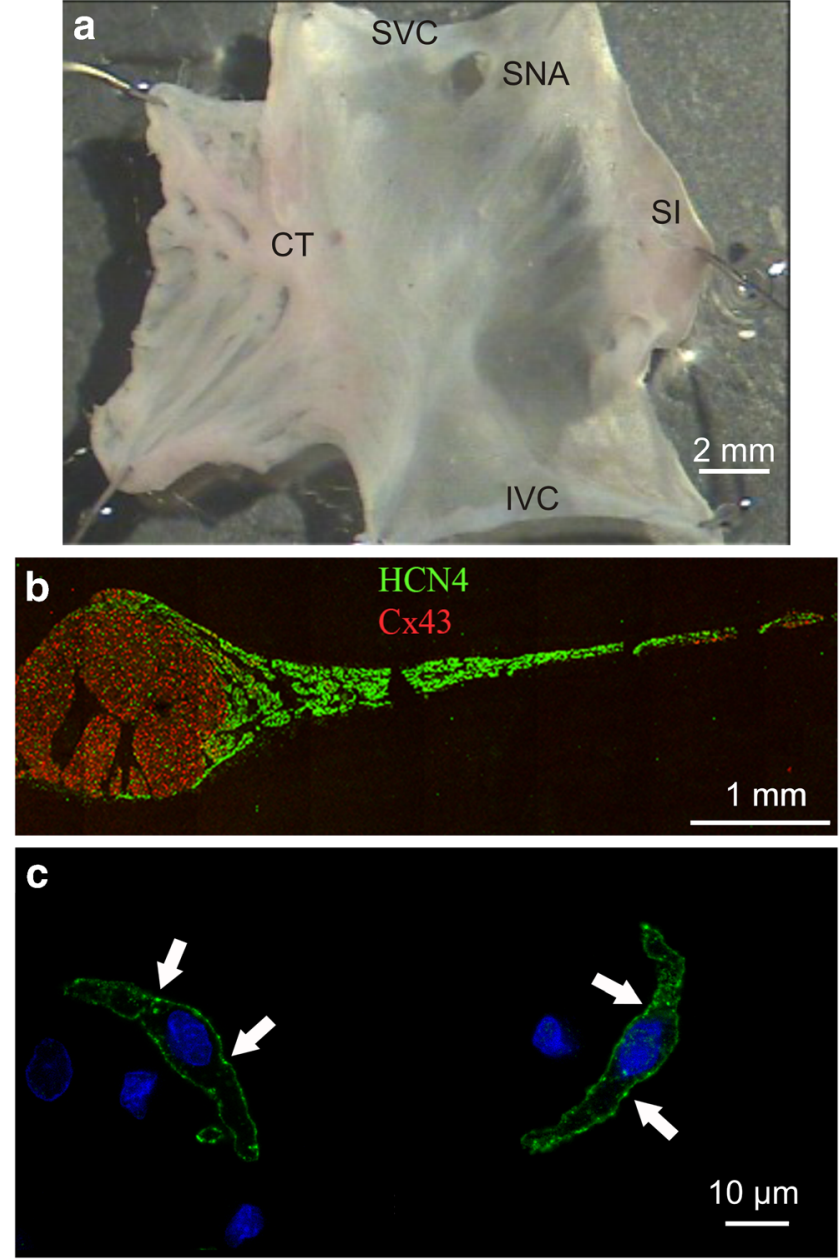

Fig. 1 Molecular identification of SAN tissue and cells. a Intact SAN isolated from the rabbit heart (endocardial view). $S V C$ superior vena cava, $I V C$ inferior vena cava, $S I$ septum interatrialis, $C T$ crista terminalis, $S N A$ sinus node artery. b HCN4 (green) and connexin 43 (red) immunolabeling of a SAN tissue slice cut perpendicularly to the intercaval region and extending from the CT to the SI. HCN4 channels are abundantly present throughout the entire SAN area, while connexin 43 is detected exclusively in the CT and in the SI. c HCN4 staining (green) of rabbit primary pacemaker SAN cells. Arrows point to membrane patches with high signal level (hot spots). Nuclei appear in blue (modified from [7] with permission)

markers of SAN cells. For example, SAN cells are rich in pacemaker "f" (HCN4) channels and Tbx3 factor but lack connexin $43(\mathrm{Cx} 43)$ and atrial natriuretic peptide (ANP) (Fig. 1b, c) [1, 7]. Opposite features are indeed typical of working atrial cells.

The AVN is a complex structure located at the base of the atrial septum at the apex of the triangle of Kock and is the sole anatomical site that allows the electrical continuity (connection) between the atria and the ventricles. The histological organization of the AVN is highly heterogeneous, and this structural complexity (compact node, central fibrous body, penetrating bundle, transitional areas) underlies the existence of two routes for electrical conduction: the fast and the 
slow pathways [1]. In the presence of pathological atrial/SAN activity, the AVN is endowed with two additional roles: during atrial tachyarrhythmias, it acts as a low-pass filter that protects the ventricles from overwhelming and deadly excitations; during marked sinus bradycardia or arrest, the AVN becomes the pacing unit of the ventricular tissue. Several studies have investigated the different cellular morphologies and action potential shapes of AVN cells. Despite the large heterogeneity, the two most representative cell types of the AVN are those presenting ovoid and rod shapes [11] (Fig. 2a). Both types can be autorhythmic even though the action potential profiles and the underlying pool of ion channels are different. In particular, the action potentials of ovoid cells closely resemble those of sinoatrial cells and thus have a higher pacing rate, while rod cells are more atrial-like and have a slower rate (Fig. 2b). Differences in automaticity are paralleled by the finding that the pacemaker $I_{\mathrm{f}}$ current is robustly expressed in ovoid cells and less so in rod cells (Fig. 2c).

\section{Pathology and genetics of SAN and AVN dysfunction}

The term SAN dysfunction (or sick sinus syndrome, SSS) is commonly used to identify various pathological conditions related to the inability of the SAN to generate heart rates that are appropriate for the physiologic needs of an individual. Various cardiac disorders such as inappropriate sinus bradycardia and tachycardia, sinus arrest, sinus-exit block,

a

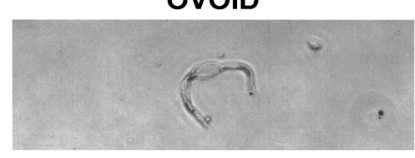

b

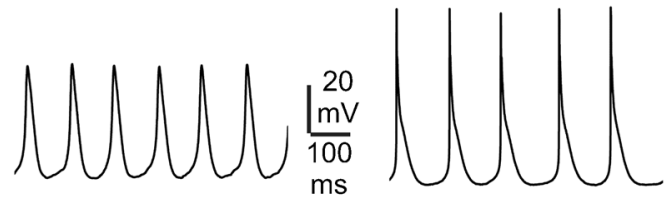

C
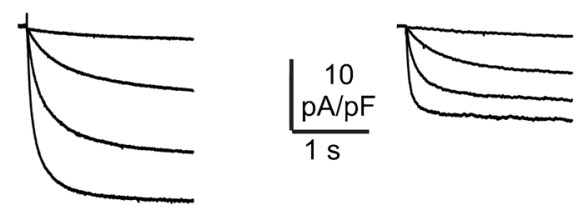

Fig. 2 Morphological and electrophysiological characteristics of AVN ovoid and rod cells. a Light microscope images of single ovoid and rod cells isolated from the rabbit AVN. b, c Spontaneous action potentials (b) and pacemaker current traces (c) recorded from typical ovoid (left) and rod (right) cells isolated from mouse AVN. Current traces were elicited by hyperpolarizing voltage steps to $-65,-85,-105$, and $-125 \mathrm{mV}$ (holding potential $=-35 \mathrm{mV}$ ). Ovoid cells beat faster and have larger currents. Recordings were carried out with the whole-cell patch-clamp technique at $35^{\circ} \mathrm{C}$ (a was from [11] with permission) alternating periods of bradycardia and tachycardia, and chronotropic incompetence are recognized as manifestations of sinus dysfunction $[12,13]$. Since SSS patients often present with exercise intolerance, presyncope, or syncope, a correct diagnosis represents an important indication for pacemaker implantation. Often, SAN dysfunction is the consequence of structural degeneration or remodeling process due to either pathological conditions such as atrial fibrillation, heart failure, and infarction or the ageing process. In addition, idiopathic degeneration of the SAN with familial inheritance has long been established. Of note is the clinical observation that while congenital idiopathic sinus dysfunction often progresses to atrial standstill, this progression is not typical of the acquired forms [12].

AVN dysfunction is a set of diseases which occur when there is a partial or total block of impulse conduction through the AVN: a condition known as atrioventricular block (AVB). Atrioventricular conduction diseases can be classified on the basis of the degree of block and particularly on the characteristics of the ECG PR interval. AVB most often occurs in association with conduction defects in the His-Purkinje system, a condition that is typical of progressive and non-progressive cardiac conduction disease. In rare cases, a congenital progressive AVB can occur in the absence of concomitant additional conduction defects [14].

Starting from the 1990s, the combined efforts of clinical practice and experimental basic science studies have identified and characterized several causative gene mutations associated with nodal syndromes. These studies have clearly established the concept that one mutation can often cause multiple clinical phenotypes (diseases) and conversely that one disease can often be associated with different types of mutations. This concept thus explains the large overlap and divergence of symptoms that can be observed within one individual, within related siblings, and among unrelated individuals carrying the same mutation/s (genotype).

In the following sections, we will discuss the genetic aspects of the SAN and AVN dysfunction considering both human gene mutations and data from transgenic animal models; information derived from the animal models can indeed be helpful in guiding genetic testing in humans.

\section{$4 \mathrm{Na}^{+}$channels}

\subsection{Cardiac Nav1.5 channels}

The SCN5A gene is located on the short arm of chromosome 3 and encodes the $\alpha$-subunit of the cardiac sodium channel (Nav1.5). In the working myocardium, Nav1.5 currents ensure the fast depolarization (phase 0 ) of the action potential, and mutant channels are associated with the Brugada syndrome $(\mathrm{BrS})$ and the LQT3 syndrome [5]. In cardiac SAN 
cells, the presence of Nav1.5 channels has long been a debated issue. There is now evidence that in most of the animal models investigated, Nav1.5 channels are either absent or scarce in the center of the node, while they are robustly expressed in the periphery where they functionally contribute to impulse conduction $[8,15-18]$. In human primary SAN cells, protein and mRNA detection experiments confirmed that Nav1.5 channel signal is small or absent (Fig. 3a) [21]; however, Verkerk et al. [22] recorded a Na ${ }^{+}$current from single human SAN cells and, based on the biophysical features, proposed an Nav1.5 origin [22]. This hypothesis contrasts with the molecular data provided by Chandler et al. [21]: a possible explanation for this

\section{a}

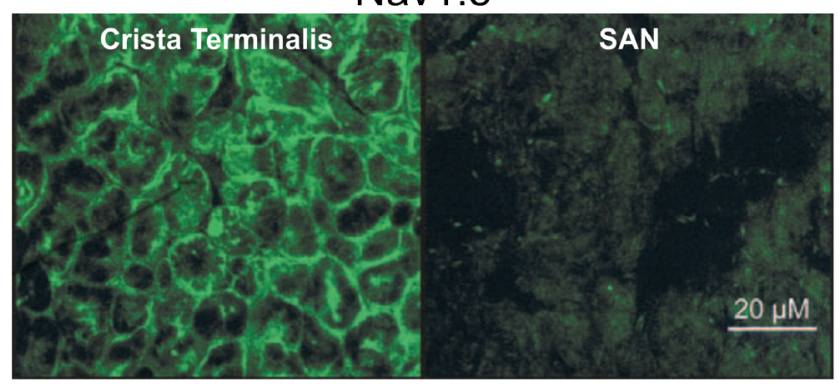

b

T187I

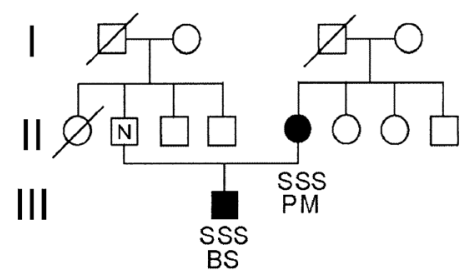

C

WT

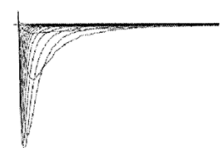

T187I

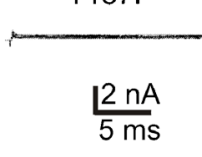

Fig. 3 Absence of Nav1.5 channels in human central SAN cells and functional consequences of loss-of-function mutations. a Immunolabeling of Nav1.5 channels (green) in the human crista terminalis (left) and SAN (right). Signal detection is strong in the region of the crista terminalis, while in the central SAN area it is virtually absent. b Pedigree and clinical features of two families carrying the heterozygous loss-of-functions mutations T187I (left) and D356N (right) of the Nav1.5 channel. Circles female subjects, squares male subjects, diagonal bars deceased subjects, solid symbols mutation carriers, symbol with " $N$ " non-mutation carrier, empty symbols no DNA test, $A V B$ atrioventricular block, $B S$ Brugada syndrome, $S S S$ sick sinus syndrome, $P M$ patient with implanted pacemaker. c Whole-cell current samples of wild-type $(W T)$ and mutant sodium channels obtained at various membrane potentials (from -90 to $+90 \mathrm{mV}$ from a holding potential of $-120 \mathrm{mV}$ ). Sodium channels were expressed in HEK293 cells in the presence of the auxiliary subunit $\mathrm{h} \beta 1$. No significant current could be measured in T187I and D356N mutants (a was from [19] with permission; $\mathbf{b}$ and $\mathbf{c}$ were modified from [20] with permission) discrepancy is that the human SAN cells used for patch-clamp experiments [22] were peripheral pacemaker cells. In addition, as will be further discussed in a following section of this review, it is possible that at least part of this current could flow through non-Nav1.5 $\mathrm{Na}^{+}$channel isoforms that are also present in SAN cells.

Despite the lack of Nav1.5 channels in primary pacemaker cells, there is ample evidence that many SCN5A mutations are associated with inherited SAN dysfunction manifestations such as bradycardia and sinus-exit block and that symptomatic and asymptomatic sinus bradycardia is also often observed both in patients affected by Brugada or LQT3 syndrome (Table 1; Fig. 3b, c).

Sinus bradycardia could occur as a consequence of either a slower diastolic depolarization or an increased duration of the action potential. In vitro characterization of biophysical defects of $\mathrm{Na}^{+}$channels associated with cardiac rate slowing indicates that loss-of-function mutations (typical of Brugada syndrome) are responsible for a slower diastolic depolarization, while gain-of-function mutations (typical of LQT3 syndrome) are responsible for the longer duration of the action potential due to the presence of a non-inactivating sodium current component $[49,56]$. In both cases, the overall cycle length increases.

Butters et al. [57] have investigated the effect of loss-offunction Nav1.5 channel mutations by developing a mathematical model of the electrical activity of both isolated SAN cells and SAN-atrium two-dimensional preparation. This study has confirmed that at the single cell level only peripheral cells are affected, but in the SAN-atrium simulation the model reproduced a slowing of both SAN rate and impulse conduction leading to SAN exit block or arrest. This study thus provides the rationale that supports the observation that mutations of the hNav1.5 channel are associated with clinical features typical of SAN dysfunction. A thorough investigation of the presence and role of mutant Nav1.5 currents in native human SAN myocytes is obviously difficult; therefore, the use of pacemaker cells derived from induced pluripotent stem cell (IPSc) obtained from patients with SAN dysfunction may represent an important future research tool.

To our knowledge, SCN5A mutations associated with pure sinus tachy-arrhythmias have not yet been identified. Whether this is still a missing piece of data or is an additional indication that Nav1.5 currents are not primarily involved with impulse generation is still an open question.

The functional integrity of $\mathrm{Na}^{+}$channels is also critical for the physiology of the AVN. The first identification of an autosomal dominant SCN5A mutation responsible for AVB was accomplished by investigating the genetic basis of two familial forms of progressive (Lev-Lenegre syndrome) and nonprogressive cardiac conduction diseases [53]. After this initial finding, several other mutations have been identified (Table 1). As shown in Table 1, SCN5A mutations associated 
Table 1 Mutations of the Nav1.5 channel (SCN5A) associated with nodal and conduction dysfunctions. The functional aspects of all mutations presented in the table have been investigated in heterologous expression studies with the patch-clamp technique. Symptoms listed were identified in the proband and/or in siblings carrying the mutation. Although several mutations displayed biophysical features compatible with both loss of and gain of function; when possible only the major phenotypic impact is listed

\begin{tabular}{|c|c|c|c|c|}
\hline $\begin{array}{l}\text { Type of mutation, } \\
\uparrow \text { G-O-F, } \downarrow \text { L-O-F }\end{array}$ & Mutation & $\begin{array}{l}\text { Impulse generation and conduction } \\
\text { dysfunctions }\end{array}$ & Additional phenotypes & Ref. \# \\
\hline$\downarrow$ & Q55X & Sinus pauses, $\mathrm{I}^{\circ} \mathrm{AVB}$ & $\mathrm{BrS}$, intraventricular conduction delay & {$[23]$} \\
\hline$\downarrow$ & R121W & SSS, PCCD & Atrial flutter, VT & {$[24]$} \\
\hline$\downarrow$ & $\begin{array}{l}\text { Compound heterozygosity } \\
\text { W156X } \\
\text { R255W }\end{array}$ & $\begin{array}{l}\mathrm{II}^{\circ} \text { AVB, severe CCD, degenerative } \\
\text { changes in the conduction system }\end{array}$ & VT of unknown origin & {$[25]$} \\
\hline$\downarrow$ & E161K & $\begin{array}{l}\mathrm{SB} \text {, sinus arrest or exit block, combinations } \\
\text { of sinoatrial and atrioventricular } \\
\text { conduction disturbances }\end{array}$ & BrS, paroxysmal atrial tachyarrhythmias & {$[26]$} \\
\hline$\downarrow$ & T187I & SB & $\mathrm{BrS}$ & {$[20]$} \\
\hline$\downarrow$ & L212P & Atrial standstill & & {$[27,28]$} \\
\hline$\downarrow$ & T220I & $\mathrm{SB}, \mathrm{AVB}$ & $\mathrm{DCM}, \mathrm{AF}, \mathrm{BBB}$ & {$[12,29]$} \\
\hline$\downarrow$ & G298S & Progressive AVB & & {$[30]$} \\
\hline$\downarrow$ & $\mathrm{D} 356 \mathrm{~N}$ & $\mathrm{III}^{\circ} \mathrm{AVB}$ & $\mathrm{BrS}$ & {$[20]$} \\
\hline$\downarrow$ & $\mathrm{R} 376 \mathrm{C}$ & Sinus block, AVB & $\mathrm{AF}$ & {$[31]$} \\
\hline$\downarrow$ & $\mathrm{R} 376 \mathrm{H}$ & AV-conduction disturbances & $\mathrm{BrS}, \mathrm{SD}$ & {$[31,32]$} \\
\hline$\uparrow$ & V411M & $\mathrm{II}^{\circ} \mathrm{AVB}$ & LQT3 & {$[33]$} \\
\hline$\downarrow$ & $\begin{array}{l}\text { T512I } \\
\text { H558R }\end{array}$ & $\mathrm{I}^{\circ}, \mathrm{II}^{\circ} \mathrm{AVB}$ & $\begin{array}{l}\text { Type } 2 \text { conduction system, (Purkinje) } \\
\text { block }\end{array}$ & [34] \\
\hline$\downarrow$ & G514C & $\begin{array}{l}\text { Bradycardia (SB or suppressed conduction } \\
\text { through atrial tissues in the vicinity of the } \\
\text { sinus node), } \mathrm{I}^{\circ} \mathrm{AVB}\end{array}$ & $\begin{array}{l}\text { Slow conduction throughout the atria } \\
\text { and ventricles }\end{array}$ & {$[35]$} \\
\hline$\downarrow$ & $\mathrm{R} 878 \mathrm{C}$ & $\begin{array}{l}\text { SB, sinus pauses, slow SAN conduction, } \\
\mathrm{I}^{\circ} \text { AVB block }\end{array}$ & Slow intraventricular conduction & {$[36]$} \\
\hline$\uparrow, \downarrow$ & A1180V & AVB & $\mathrm{AF}, \mathrm{DCM}$ & {$[37]$} \\
\hline$\downarrow$ & $\mathrm{D} 1275 \mathrm{~N}$ & Sinus node dysfunction, SB, AVB & $\mathrm{BBB}, \mathrm{AF}$, atrial flutter, DCM, CHF & {$[28,29]$} \\
\hline$\downarrow$ & P1298L & $\mathrm{I}^{\circ} \mathrm{AVB}$ & & {$[12]$} \\
\hline$\downarrow$ & G1408R & $\mathrm{I}^{\circ} \mathrm{AVB}, \mathrm{CCD}$ & BrS, prolonged QRS & {$[12,38]$} \\
\hline$\downarrow$ & $\begin{array}{l}\text { Compound heterozygosity } \\
\text { P1298L } \\
\text { G1408R }\end{array}$ & SSS & & {$[12]$} \\
\hline$\downarrow$ & W1421X & $\mathrm{SSS}, \mathrm{SB}, \mathrm{I}^{\circ} \mathrm{AVB}, \mathrm{CCD}$ & $\mathrm{BBB}, \mathrm{SD}$ & {$[28,39]$} \\
\hline$\downarrow$ & 1493delK & $\mathrm{SB}, \mathrm{I}^{\circ} \mathrm{AVB}, \mathrm{CCD}$ & $\mathrm{SD}$ & {$[40]$} \\
\hline$\uparrow, \downarrow$ & $\Delta \mathrm{K} 1500$ & Sinus pauses, $\mathrm{I}^{\circ} \mathrm{AVB}$ & LQT3, BrS, BBB, SD & {$[41]$} \\
\hline$\uparrow$ & delKPQ1505-1507 & PCCD, SB & LQT3, BrS & {$[42]$} \\
\hline$\uparrow$ & delQKP1507-1509 & SB, sinus arrhythmia & LQT3 & {$[43]$} \\
\hline$\downarrow$ & $\mathrm{K} 1578 \mathrm{fs} / 52$ & $\mathrm{SSS}$, sinus arrest, $\mathrm{I}^{\circ} \mathrm{AVB}$, & $\mathrm{BrS}, \mathrm{SD}$ & {$[20]$} \\
\hline$\downarrow$ & $\mathrm{D} 1595 \mathrm{~N}$ & Progressive AVB & & {$[30]$} \\
\hline$\downarrow$ & $\begin{array}{l}\text { Compound heterozygosity } \\
\text { delF1617 } \\
\text { R1632H }\end{array}$ & Bradycardia, atrial standstill & $\begin{array}{l}\text { Prolonged QRS and prolonged } \\
\text { His-ventricle conduction time }\end{array}$ & {$[12]$} \\
\hline$\downarrow$ & R1623X & Sinus arrest, $\mathrm{I}^{\circ} \mathrm{AVB}$ & $\mathrm{BrS}$ & {$[12,20]$} \\
\hline$\downarrow$ & $\begin{array}{l}\text { Compound heterozygosity } \\
\text { R1623X } \\
\text { T220I }\end{array}$ & Absent $P$ waves, sinus pauses & & {$[12]$} \\
\hline$\downarrow$ & $\mathrm{R} 1632 \mathrm{H}$ & $\mathrm{I}^{\circ} \mathrm{AVB}$ & & {$[12]$} \\
\hline$\downarrow$ & S1710L & $\mathrm{I}^{\circ} \mathrm{AVB}$ & Ventricular fibrillation & {$[44]$} \\
\hline$\uparrow$ & V1763M & Fetal bradycardia, postnatal $\mathrm{II}^{\circ} \mathrm{AVB}$ & VT, LQT3 & {$[45]$} \\
\hline$\uparrow$ & V1777M & $\mathrm{II}^{\circ} \mathrm{AVB}$ & LQT3 & {$[46]$} \\
\hline$\uparrow$ & E1784K & $\mathrm{SB}$, sinus pauses & LQT3, SD & {$[47]$} \\
\hline$\uparrow$ & D1790G & Sinus arrest & LQT3 & {$[48]$} \\
\hline
\end{tabular}


Table 1 (continued)

\begin{tabular}{llll}
\hline $\begin{array}{l}\text { Type of mutation, } \\
\uparrow \text { G-O-F, } \downarrow \text { L-O-F }\end{array}$ & Mutation & $\begin{array}{l}\text { Impulse generation and conduction } \\
\text { dysfunctions }\end{array}$ & Additional phenotypes \\
\hline$\uparrow, \downarrow$ & 1795 insD & SB, sinus pauses & LQT3, BrS, SD \\
$\downarrow$ & L1821fs $/ 10$ & SB, sinus pauses, CCD, II ${ }^{\circ}$ AVB & VT, BBB, atrial flutter \\
$\uparrow, \downarrow$ & SB, sinus pauses, I I AVB & AF, atrial flutter & [49, 50] \\
$\downarrow$ & R1860Gfs*12 & AVB, PCCD & BBB \\
$\downarrow$ & IVS22_2T_C & $\mathrm{I}^{\circ}$ AVB, CCD & BBB \\
\hline
\end{tabular}

$\uparrow$ gain of function (G-O-F), $\downarrow$ loss of function (L-O-F), $A V B$ atrioventricular block, $B r S$ Brugada syndrome, $S S S$ sick sinus syndrome, $P C C D$ progressive cardiac conduction disease, $C C D$ cardiac conduction disease, $V T$ ventricular tachycardia, $S B$ sinus bradycardia, $D C M$ dilated cardiomyopathy, $A F$ atrial fibrillation, $B B B$ bundle branch block, $S D$ sudden death, $L Q T 3$ type 3 long QT syndrome, $C H F$ congestive heart failure

with AVN dysfunctions have been observed alone or in combination with Brugada and/or LQT3 syndromes. The mechanisms by which loss-of-function and gain-of-function mutations functionally converge toward a common pathological outcome in the AVN (AVB) may be similar to the one described above for SAN bradycardic dysfunction. However, this hypothesis might be an oversimplification given the higher complexity of the physiology of the AVN conduction.

We can thus conclude that the biophysical properties of SCN5A mutant channels associated with nodal dysfunction have been largely identified. However, when the focus is moved from the bench to the bedside, a large overlapping of phenotypes [5], together with incomplete penetrance and variability, often complicate the possibility to adopt a personalized (mutation-tailored) clinical treatment.

\subsection{Other $\mathrm{Na}^{+}$channel isoforms and auxiliary $\beta$-subunits}

The first identification of a non-Nav1.5 isoform was carried out in neonatal rabbit SAN cells, where a Nav1.1 tetrodotoxin (TTX)-sensitive current was shown to be selectively expressed during the first month after birth and to significantly contribute to the pacemaker activity $[15,58,59]$. Several other studies have further investigated the presence of Nav1.1 and of other isoforms in the adult mammalian SAN, and there is now ample evidence that Nav1.1 (SCN1A), Nav1.2 (SCN2A), Nav1.3 (SCN3A), and Nav1.6 (SCN8A) channels are present in SAN cells, although substantial differences in the expression profiles exist among different species [18, 60, 61].

In the human SAN, the presence of detectable albeit low quantity of Nav1.1, Nav1.2, and Nav1.4 (SCN4A) channels was confirmed by Chandler and colleagues [21]. Based on this evidence, it is therefore possible that the INa current originally recorded in the human SAN [22] may be at least partly associated with these isoforms.

The presence of non-Nav1.5 channel isoforms has also been investigated in the AVN of several species, and positive identification has been accomplished for Nav1.1, Nav1.2,
Nav1.3, and Nav1.7 (SCN9A) [60, 62]. In humans, Greener et al. [63] have confirmed the presence of Nav1.1, Nav1.3, Nav1.6, and Nav1.7, but their quantitative expression is about tenfold lower than the Nav1.5 channels.

Currently, there is no evidence of mutations of non-Nav1.5 isoforms associated with SAN or AVN dysfunction in humans. However, it is interesting to consider that in a mouse model, the conditional and cardiac-specific heterozygous knockout of the SCN1A gene causes a reduction of heart rate, an increase in the PR interval, and an increase in the heart rate variability [64]. An additional confirmation of the pathophysiological roles of Nav1.1 channels comes from the evidence that in a rat model of heart failure (HF), a profound decline of Nav1.1 (-60.7\%) and Nav1.6 (-47.4\%) isoforms likely contributes to the impairment of SAN function [61]. It remains an open question whether a remodeling of Nav1.1 channels also occurs in human HF patients where a depressed SAN function is often observed [65].

We can thus suggest that non-cardiac (non-Nav1.5) $\mathrm{Na}^{+}$ channels should also be investigated when looking for the genetic basis of nodal dysfunction.

$\mathrm{Na}^{+}$channel accessory $\beta$-subunits are important modulators of the pore-forming $\alpha$-subunits, and therefore their functional integrity is also extremely relevant in order to ensure proper $\mathrm{Na}^{+}$currents. Loss-of-function mutations of the $\mathrm{Na}_{\mathrm{v}} \beta 1$ (SCN1B) protein have indeed been reported to be associated with the Brugada syndrome and/or conduction disease [66]. Further indication supporting a pathological role of $\mathrm{Na}_{\mathrm{v}} \beta 1$ defects comes from a $\mathrm{Na}_{\mathrm{v}} \beta 1$ null mouse which exhibits both cardiac (prolonged QT and bradycardia) and neurological disorders [67].

\section{HCN4 channels}

Pacemaker f-channels belong to the hyperpolarizationactivated cyclic nucleotide-gated ( $\mathrm{HCN}$ ) channel family and have long been recognized for their primary role in generating and modulating the automaticity of SAN cells [9, 68]. HCN4 
is the principal isoform ( $\sim 80 \%$ of the total $I_{\mathrm{f}}$ current $)$ expressed in the conductive tissue and in particular in the $\mathrm{SAN}$, and screening analysis performed on arrhythmic patients has identified several HCN4 mutations associated with symptomatic and non-symptomatic alterations of the sinus rhythm (Table 2; Fig. 4a).

All the mutations identified thus far are of the loss-offunction type, and their resulting phenotypes are compatible with a reduced contribution of the pacemaker current to the diastolic depolarization of SAN cells in resting conditions.

Recently, it has been demonstrated that selective knockout of HCN4 channels in adult transgenic mouse causes sinus bradycardia and AVB that progresses from PQ prolongation to complete heart block (Fig. 4b) [78]. While the sinus bradycardia was obviously predictable, the presence of the AVB was completely unexpected. The evidence that a reduction of the pacemaker current (of about $75 \%$ both in SAN and AVN cells) interferes with the conduction of the impulse through the AVN is not of immediate interpretation. Indeed these data challenge the current view that the sole role of the $\mathrm{HCN} 4$ current is to ensure subsidiary pacemaker AVN activity when the primary impulse from the SAN is pathologically impaired. Although it is only speculative, a possible interpretation of the knockout data is that proper SAN impulse propagation throughout the AVN requires AVN cells to be partially depolarized by their own spontaneous diastolic phase; if this spontaneous background depolarization is altered, then also impulse propagation through the AVN is impaired.

Of extreme clinical interest is the association of atrial fibrillation (AF) with the presence of spontaneous arrhythmogenic

Table 2 Mutations of the pacemaker (HCN4) channels associated with nodal dysfunctions. The functional aspects of all mutations presented in the table have been investigated in heterologous expression studies with activity localized in proximal part of the pulmonary veins (PVs) near the left atrium. The identification of this region as an important therapeutic target for the treatment of $\mathrm{AF}$ has guided the seminal work of several groups which have demonstrated that focal radioablation of the tissue around the PVs often successfully resolves AF. Investigation of the cytological organization of the pulmonary sleeves in tissue samples from human AF patients has confirmed the presence of cells similar to those of the conduction tissue [79]. This information, together with the established evidence that in small mammals the $I_{\mathrm{f}}$ current is highly expressed in this region, raises the question whether familial forms of AF arising from the pulmonary vein sleeves are related to a pathological alteration of the $I_{\mathrm{f}}$ expression [80].

\section{$6 \mathrm{Ca}^{2+}$ channels and $\mathrm{Ca}^{2+}$ handling proteins}

\section{1 $\mathrm{Ca}^{2+}$ channels}

Studies on animal models have shown that voltage-dependent $\mathrm{L}$ - and T-type $\mathrm{Ca}^{2+}$ currents and intracellular $\mathrm{Ca}^{2+}$ oscillation provide an important contribution to support the pacemaker activity of sinoatrial node cells. In central nodal cells, $\mathrm{Ca}^{2+}$ currents (L-type: Cav1.2 and Cav1.3 channels; T-type: Cav3.1 channels) indeed provide a depolarizing force that both supports the second part of the diastolic depolarization and ensures the upstroke of the action potential [81, 82].

Mangoni et al. have shown that transgenic Cav3.1 $1^{-/}$mice, lacking the T-type calcium currents, present with a moderate

the patch-clamp technique. Symptoms listed were identified in the proband and/or in siblings carrying the mutation

\begin{tabular}{|c|c|c|c|c|}
\hline $\begin{array}{l}\text { Type of mutation, } \\
\uparrow \text { G-O-F, } \downarrow \text { L-O-F }\end{array}$ & Mutation & Impulse generation and conduction dysfunctions & Additional phenotypes & Ref. \# \\
\hline$\downarrow$ & A414G & SB & LVNC, AF, atrial standstill & [69] \\
\hline$\downarrow$ & G480R & SB & & {$[70]$} \\
\hline$\downarrow$ & $\mathrm{Y} 481 \mathrm{H}$ & SB & $\begin{array}{l}\text { LVNC, AF, degeneration of the mitral valve; } \\
\text { polymorphic ventricular, extrasystoles } \\
\text { during exercise }\end{array}$ & [69] \\
\hline$\downarrow$ & G482R & $\mathrm{SB}, \mathrm{I}^{\circ} \mathrm{AVB}$, impaired chronotropic capacity & $\begin{array}{l}\text { LVNC, intermittent ectopic atrial rhythms, mitral } \\
\text { valve prolapse, out-of-hospital cardiac arrest }\end{array}$ & {$[69,71$} \\
\hline$\downarrow$ & $\mathrm{A} 485 \mathrm{~V}$ & SB & $\begin{array}{l}\text { Out-of-hospital cardiac arrest during extreme } \\
\text { exercise, inducible AF, paroxysmal AF }\end{array}$ & {$[72]$} \\
\hline$\downarrow$ & $\mathrm{K} 530 \mathrm{~N}$ & SB, sinus pauses, tachycardia-bradycardia syndrome & Persistent AF & {$[73]$} \\
\hline$\downarrow$ & D553N & SB & $\begin{array}{l}\text { QT prolongation; torsade de pointes, cardiac } \\
\text { arrest for } 40 \mathrm{~s} \text { followed by polymorphic VT }\end{array}$ & {$[74]$} \\
\hline$\downarrow$ & $573 X$ & SB, chronotropic incompetence during exercise & Intermittent $\mathrm{AF}$ & {$[75]$} \\
\hline$\downarrow$ & S672R & SB & & [76] \\
\hline$\downarrow$ & $695 \mathrm{X}$ & $\begin{array}{l}\text { SB, episodes of distinctive sinus arrhythmia linked } \\
\text { to adrenergic stress }\end{array}$ & $\begin{array}{l}\text { LVNC, susceptibility to atrial and ventricular } \\
\text { premature beats, mitral valve prolapse }\end{array}$ & {$[71,77$} \\
\hline
\end{tabular}

$S B$ sinus bradycardia, $L V N C$ left ventricular noncompaction cardiomyopathy, $A F$ atrial fibrillation, $A V B$ atrioventricular block, $V T$ ventricular tachycardia 
a

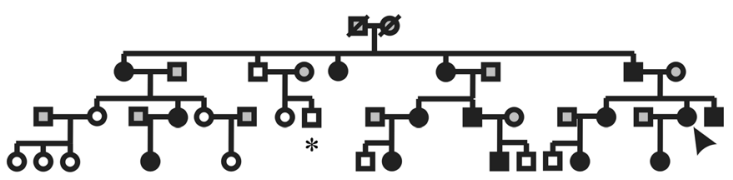

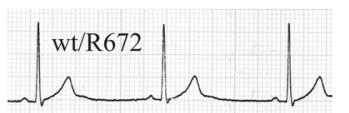

b

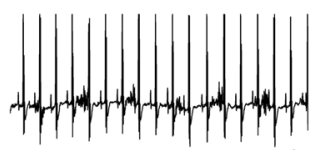

\section{$2 \mathrm{~s}$}

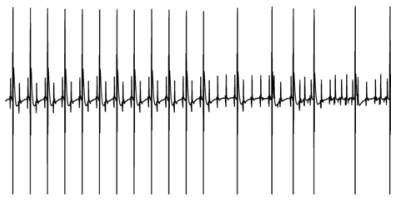

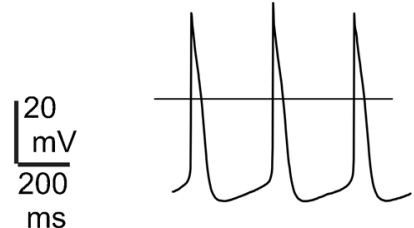

Fig. 4 Impairment of HCN4 channel contribution to cardiac pacemaker causes SAN and AVN dysfunction. a Top pedigree of a four-generation family with an inherited form of sinus bradycardia associated with the S672R mutation of the HCN4 channel. Persons carrying the heterozygous S672R mutation are represented by solid symbols, wt (control) individuals are indicated by open symbols, and gray symbols are genetically unrelated individuals. a Bottom electrocardiograms of a control individual (asterisk in the pedigree) and of the proband carrying the mutation (arrow in the pedigree); resting heart rates were 80 and 43 beats per minute, respectively. b Top telemetric ECG recordings from a freely moving transgenic mouse prior to $(l e f t)$ and after 4 days of cardiac specific and inducible knockout of the HCN4 channel (right). Sinus bradycardia and AVB are evident upon HCN4 knockout. b Bottom spontaneous action potentials recorded from single SAN cells isolated from a control (left) mouse and a transgenic mouse after 4 days of cardiac specific and inducible knockout of the HCN4 channel (right). The slowing of spontaneous rate is evident (a was modified from [76] with permission; b was modified from [78] with permission)

reduction of the intrinsic heart rate and have a first-degree AVB [83]. No evidence of mutations affecting Cav3.1 channels has been reported in humans. However, a possible pathological association between loss-of-function of T-type channels and bradycardia and atrioventricular block is found in pediatric patients affected by congenital heart block [84] caused by IgG-induced inhibition of calcium T- and L-type channels in children of mothers affected by an autoimmune disease of rheumatic origin [85].

In 2011, the first homozygous loss-of-function mutation (1208_1209insGGG) of the human L-type Cav1.3 channel was identified in patients affected by the following symptoms: severe to profound deafness, resting bradycardia (32$52 \mathrm{bpm}$ ), increased heart rate variability, altered atrioventricular conduction, and junctional escape rhythm; SAN arrest and exit block were also observed [86] (Fig. 5). This complex disorder was termed SAN dysfunction and deafness

syndrome, and the presence of cardiac as well as hearing impairment is reminiscent of the phenotype observed in Cav1.3 knockout mice which also show SAN and AVN dysfunction as well as deafness $[87,88]$.

\section{$6.2 \mathrm{Ca}^{2+}$ handling proteins}

In working myocytes, the intracellular control of the $\mathrm{Ca}^{2+}$ concentration is a fundamental aspect of the excitation-contraction coupling process. Intracellular $\mathrm{Ca}^{2+}$ oscillations also represent an important mechanism that, together with plasma membrane ion currents, governs the automaticity of spontaneously beating SAN cells. It is therefore expected that mutations of $\mathrm{Ca}^{2+}$ handling proteins may have important pathological consequences both in working myocytes and in myocytes of the conduction tissue.

Calsequestrin (CASQ2) is a sarcoplasmic $\mathrm{Ca}^{2+}$-binding protein, and ryanodine receptor type 2 (RYR2) is a calcium channel of the sarcoplasmic membrane. Loss-of-function mutations of CASQ2 and RyR2 have been associated with catecholaminergic polymorphic ventricular tachycardia (CPVT),

\section{a}

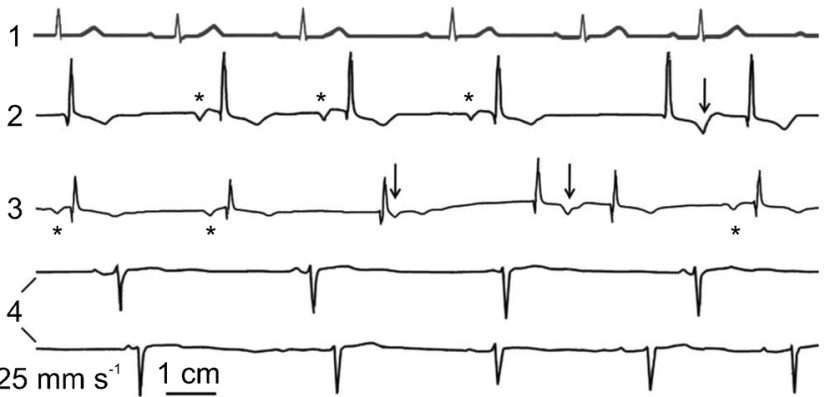

b

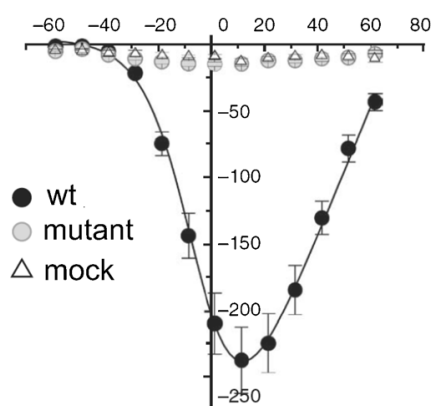

Fig. 5 Clinical and cellular phenotypic expressions of mutant Cav1.3 channels associated with SAN dysfunction. a Electrocardiograms obtained from a wild-type subject ( 1 ) and three homozygous carriers (2, $3,4)$ of the c.1208_1209insGGG (p.403_404insGly) mutation of the CACNA1D gene (Cav1.3 calcium channel). Mutant carriers are clinically affected by SAN dysfunction. Asterisks identify P waves that precedes ventricular activation (QRS complexes), and arrows identify overlapping of $\mathrm{P}$ and $\mathrm{T}$ waves. A large variability of the $\mathrm{P}-\mathrm{P}$ and $\mathrm{R}-\mathrm{R}$ intervals are observed in arrhythmic patients. b Current-voltage relation of heterologous expression of Cav1.3 channels; no significant current can be measured in mutant p.403 404insGly channels (modified from [86] with permission) 
and CPVT patients often present with SAN bradycardia [89, 90].

The $\mathrm{Na}^{+} / \mathrm{Ca}^{2+}$ exchanger (NCX1) is an important effector of the $\mathrm{Ca}^{2+}$-clock mechanism since it provides a depolarizing current that contributes to the pacemaker activity of SAN cells [10]. At present, there are no reports on mutations of NCX1 associated with nodal dysfunction; however, recent studies in mice have shown that partial ablation (70-80 \% knockout) of NCX1 does not affect both in vivo and ex vivo basal heart rates but severely impairs the $\beta$-adrenergic-induced response, while its complete knockout fully eliminates the SAN pacemaker activity [91, 92]. Given the substantial difference between the two phenotypes, it can be hypothesized that in the full knockout model, the severe impairment of SAN cell function can be associated both to the lack of electrogenic activity of the NCX1 pump and to substantial impairment of multiple additional pathways associated with the altered $\mathrm{Ca}^{2+}$ homeostasis.

\section{Popdc proteins and twin-pore potassium (K2P) channels}

The Popeye domain-containing gene (Popdc) family is a class of membrane proteins largely present in the heart with an evolutionary conserved structural element (the Popeye domain), which binds to the cellular second messenger cAMP. Interestingly, there is a structural similarity between the Popeye domain and the cyclic nucleotide binding domains of the cardiac pacemaker (HCN) channels and of the cAMPdependent protein kinase (PKA) [93]. In mice, Popdc1 and Popdc2 isoforms are highly expressed in the entire cardiac conduction system, and their knockout induces the appearance of severe sinus node dysfunction, but only in the presence of stress-induced conditions and in an age-dependent manner [94]. The histological analysis of these arrhythmic mutant mice demonstrates a loss of HCN4 positive pacemaker cells [94]. Also, functional knockout of Popdc2 in the zebrafish model also induces severe baseline brady-arrhythmias and AVB [95].

One hypothesis that can explain how the Popdc pathway modulates the cardiac automaticity is based on the observation that Popdc proteins are functional modulators of TREK-1 channels which are members of the twin-pore potassium ion (K2P) channel family [94], and K2P channels are known to control the excitability, the resting membrane potential, and the repolarization phase of cardiomyocytes [96]. Although TREK1 channels appear to be absent from the human SAN, other members of this family such as TWIK1 and TASK1 have been identified [21]. Interestingly, studies of SAN remodelling associated with heart failure (HF) in a rat model have shown that TWIK1, TWIK2, and TASK1 are upregulated during HF and could thus represent a mechanism contributing to the decreased intrinsic heart rate associated with HF [97]. Also indicative is the finding that in Drosophila a K2P channel (ORK1) directly contributes to setting the duration of the diastolic depolarization [98]. Additional proposed mechanisms of the action of Popdc proteins include (a) possible interactions with other ion channels such as HCN or Na channels, (b) a cAMP-dependent role as transcriptional regulators since Popdc proteins have been found also within cell nucleus, and (c) interaction with caveolin-3 since loss of Popdc1 impairs both the caveolar size and the correct trafficking of proteins normally associated with caveolae [99, 100].

Whether these genes are also functionally relevant in the cardiac settings of human nodal diseases remains to be determined.

\section{Lamin, emerin, nesprin}

Lamin $\mathrm{A} / \mathrm{C}$, emerin, and nesprin proteins are part of an intricate protein network of muscle cells that connect the nuclear envelope to the cell nucleo- and cytoskeleton. Interestingly, lamins are considered to be the ancestors of all intermediate filaments. Mutations affecting the correct functions of these genes have been linked to skeletal muscle (Emery-Dreifuss muscular dystrophy) and cardiac diseases including conduction dysfunction [6]. A clear understanding of the functional role and pathological aspects of these proteins is still lacking; however, it may be that the integrity of this protein network is necessary for proper tissue-dependent chromatin dynamics and gene expression [101].

\section{Ankyrin-B and caveolin-3}

Ankyrins are a class of proteins ubiquitously expressed in excitable and non-excitable cells whose function is to connect integral membrane proteins to the cytoskeleton. Far from being purely passive structural elements, ankyrins contribute to maintaining the proper spatial and functional organization of ion channels, transporters $\left(\mathrm{Na}^{+} / \mathrm{K}^{+}\right.$exchanger, $\mathrm{Na}^{+} / \mathrm{K}^{+}$ ATPase), and $\mathrm{Ca}^{2+}$ handling proteins of the sarcoplasmic reticulum such as inositol 1,4,5, trisphosphate (InsP3) receptor, and ryanodine receptor (RyR2) [102]. It is thus not surprising that loss-of-function mutations of ankyrin-B, an isoform largely expressed in the heart, profoundly alter the proper homeostatic control of $\mathrm{Ca}^{2+}$ and $\mathrm{Na}^{+}$ions, thus causing a critical substrate for the occurrence of mechano-electrical instability. This condition can then precipitate to a pathological manifestation known as Ankyrin-B syndrome. Symptoms associated with this syndrome include sinus arrhythmias, prolonged QT, torsade de pointes, and atrial fibrillation $[102,103]$. Sinus node dysfunction is observed in a relevant fraction (up to $75 \%$ ) of 
individuals affected by the Ankyrin-B syndrome, while QT prolongation is rarer and only occurs in the most severe clinical manifestations [103-105]. Of relevance is also the evidence that a distinct ankyrin protein (ANK-G) selectively interacts with Nav1.5 channels (and with Nav.12, Nav1.6), and patients presenting a mutation in the Nav1.5 channel that disrupt this interaction present with Brugada syndrome [102].

Caveolin-3 (CAV3) are integral membrane proteins abundantly present in cardiac and skeletal myocytes where they contribute to the formation of caveolae which are $\Omega$-shaped invaginations of the membrane. Caveolar organization of the membrane favors the co-localization of ion channels, transporters, receptors, and several other proteins in order to ensure optimal spatial and time confinement of local signal transduction. In the heart, CAV3 proteins are virtually present in all myocytes and particularly in SAN cells [106]. Genetic defects of caveolin-3 have been associated both with LQT9 and with sudden infant death syndromes, and the underlying mechanism responsible is the large increase of the late component (up to fivefold) of the Nav1.5 sodium current which is caused by these mutations [107, 108]. Interestingly, patients carrying the T78M mutations also displayed marked sinus bradycardia. The proposed mechanism for this T78M-dependent bradycardia is a modification of the Nav1.5 current which is expressed in peripheral SAN cells. Since Cav3 is also largely present in the center of the SAN, and it functionally interacts with several other ion channels, among which the HCN channels [109], it is also possible that the sinus bradycardia observed in patients carrying the T78M mutation might be caused by the disruption of these additional interactions with other channels.

\section{Protein kinase PRKAG2}

The 5' AMP-activated protein kinase (AMPK) is a metabolic sensor that couples cardiac cell physiology to the metabolic state of the heart and is activated by AMP and inhibited by ATP. If the energetic content of the cells becomes too low, the AMPK will counteract this condition by limiting ATP consumption and by activating ATP-producing pathways. Mutations of the PRKAG2 protein are often associated with ventricular pre-excitation (typical of the Wolff-Parkinson-White syndrome) and with AVB and sinus bradycardia $[3,6,110]$. Cardiac hypertrophy of working and conductive myocytes due to an exaggerated glycogen deposition is also typically observed. At present, a convincing molecular explanation for the clinical phenotypes is still missing. While it is possible that the structural modifications due to the hypertrophic state can lead to electrical remodeling and thus to conduction disorders, it cannot be excluded that mutant PRKAG2 proteins may play a role in controlling the expression and modulation of ion channel of conductive cardiomyocytes.

\section{Conclusions}

The SAN and the AVN together with the His-Purkinje system ensure the appropriate generation and delivery of the electrical impulse to the working myocardium. The physiological functions of these strategic regions can occur only if all the structural and electrical features of these cells are not impaired by acquired or inherited dysfunctions. In recent years, combined efforts of clinical practice and experimental basic science studies have identified and characterized several causative gene mutations associated with the nodal syndromes. One concept that emerges strongly from these studies is that even a single mutation can induce several phenotypical manifestations, and therefore overlapping syndromes are often simultaneously present. The presence of incomplete penetrance and variability often further increases this complexity. Taken together, these concepts explain the clinical observation that "pure nodal dysfunctions", i.e., dysfunctions of the SAN and AVN in the absence of any additional cardiac disorders, are rare. Despite this complexity, the genetic identification of mutations associated with inherited nodal dysfunctions is becoming a valuable clinical element that may be utilized in order to optimize the clinical therapeutic approach for each patient.

Acknowledgments The authors declare that they have no conflict of interest.

Open Access This article is distributed under the terms of the Creative Commons Attribution License which permits any use, distribution, and reproduction in any medium, provided the original author(s) and the source are credited.

\section{References}

1. Dobrzynski, H., Anderson, R. H., Atkinson, A., Borbas, Z., D'Souza, A., Fraser, J. F., et al. (2013). Structure, function and clinical relevance of the cardiac conduction system, including the atrioventricular ring and outflow tract tissues. Pharmacology and Therapeutics, 139(2), 260-288.

2. Baruscotti, M., Barbuti, A., \& Bucchi, A. (2010). The cardiac pacemaker current. Journal of Molecular and Cellular Cardiology, 48(1), 55-64.

3. Beinart, R., Ruskin, J., \& Milan, D. (2010). The genetics of conduction disease. Heart Failure Clinics, 6(2), 201-214.

4. Benson, D. W. (2004). Genetics of atrioventricular conduction disease in humans. The Anatomical Record Part A: Discoveries in Molecular, Cellular, and Evolutionary Biology, 280(2), 934 939.

5. Remme, C. A. (2013). Cardiac sodium channelopathy associated with SCN5A mutations: electrophysiological, molecular and genetic aspects. The Journal of Physiology, 591(Pt 17), 4099-4116.

6. Wolf, C. M., \& Berul, C. I. (2006). Inherited conduction system abnormalities - one group of diseases, many genes. Journal of Cardiovascular Electrophysiology, 17(4), 446-455.

7. Brioschi, C., Micheloni, S., Tellez, J. O., Pisoni, G., Longhi, R., Moroni, P., et al. (2009). Distribution of the pacemaker HCN4 
channel mRNA and protein in the rabbit sinoatrial node. Journal of Molecular and Cellular Cardiology, 47(2), 221-227.

8. Honjo, H., Boyett, M. R., Kodama, I., \& Toyama, J. (1996). Correlation between electrical activity and the size of rabbit sino-atrial node cells. The Journal of Physiology, 496(Pt 3), 795-808.

9. DiFrancesco, D. (2010). The role of the funny current in pacemaker activity. Circulation Research, 106(3), 434-446.

10. Lakatta, E. G., \& DiFrancesco, D. (2009). What keeps us ticking: a funny current, a calcium clock, or both? Journal of Molecular and Cellular Cardiology, 47(2), 157-170.

11. Munk, A. A., Adjemian, R. A., Zhao, J., Ogbaghebriel, A., \& Shrier, A. (1996). Electrophysiological properties of morphologically distinct cells isolated from the rabbit atrioventricular node. The Journal of Physiology, 493(Pt 3), 801-818.

12. Benson, D. W., Wang, D. W., Dyment, M., Knilans, T. K., Fish, F. A., Strieper, M. J., et al. (2003). Congenital sick sinus syndrome caused by recessive mutations in the cardiac sodium channel gene (SCN5A). The Journal of Clinical Investigation, 112(7), 10191028.

13. Mangrum, J. M., \& DiMarco, J. P. (2000). The evaluation and management of bradycardia. The New England Journal of Medicine, 342(10), 703-709.

14. Baruteau, A. E., Behaghel, A., Fouchard, S., Mabo, P., Schott, J. J., Dina, C., et al. (2012). Parental electrocardiographic screening identifies a high degree of inheritance for congenital and childhood nonimmune isolated atrioventricular block. Circulation, 126(12), 1469-1477.

15. Baruscotti, M., DiFrancesco, D., \& Robinson, R. B. (1996). A TTX-sensitive inward sodium current contributes to spontaneous activity in newborn rabbit sino-atrial node cells. The Journal of Physiology, 492(Pt 1), 21-30.

16. Kodama, I., Nikmaram, M. R., Boyett, M. R., Suzuki, R., Honjo, H., \& Owen, J. M. (1997). Regional differences in the role of the $\mathrm{Ca}^{2+}$ and $\mathrm{Na}^{+}$currents in pacemaker activity in the sinoatrial node. The American Journal of Physiology, 272(6 Pt 2), H2793-2806.

17. Remme, C. A., Verkerk, A. O., Hoogaars, W. M., Aanhaanen, W. T., Scicluna, B. P., Annink, C., et al. (2009). The cardiac sodium channel displays differential distribution in the conduction system and transmural heterogeneity in the murine ventricular myocardium. Basic Research in Cardiology, 104(5), 511-522.

18. Maier, S. K., Westenbroek, R. E., Yamanushi, T. T., Dobrzynski, H., Boyett, M. R., Catterall, W. A., et al. (2003). An unexpected requirement for brain-type sodium channels for control of heart rate in the mouse sinoatrial node. Proceedings of the National Academy of Sciences of the United States of America, 100(6), $3507-3512$

19. Dobrzynski, H., Boyett, M. R., \& Anderson, R. H. (2007). New insights into pacemaker activity: promoting understanding of sick sinus syndrome. Circulation, 115(14), 1921-1932.

20. Makiyama, T., Akao, M., Tsuji, K., Doi, T., Ohno, S., Takenaka, K., et al. (2005). High risk for bradyarrhythmic complications in patients with Brugada syndrome caused by SCN5A gene mutations. Journal of the American College of Cardiology, 46(11), 2100-2106.

21. Chandler, N. J., Greener, I. D., Tellez, J. O., Inada, S., Musa, H., Molenaar, P., et al. (2009). Molecular architecture of the human sinus node: insights into the function of the cardiac pacemaker. Circulation, 119(12), 1562-1575.

22. Verkerk, A. O., Wilders, R., van Borren, M. M., \& Tan, H. L. (2009). Is sodium current present in human sinoatrial node cells? International Journal of Biological Sciences, 5(2), 201-204.

23. Makita, N., Sumitomo, N., Watanabe, I., \& Tsutsui, H. (2007). Novel SCN5A mutation (Q55X) associated with age-dependent expression of Brugada syndrome presenting as neurally mediated syncope. Heart Rhythm, 4(4), 516-519.
24. Holst, A. G., Liang, B., Jespersen, T., Bundgaard, H., Haunso, S., Svendsen, J. H., et al. (2010). Sick sinus syndrome, progressive cardiac conduction disease, atrial flutter and ventricular tachycardia caused by a novel SCN5A mutation. Cardiology, 115(4), 311316.

25. Bezzina, C. R., Rook, M. B., Groenewegen, W. A., Herfst, L. J., van der Wal, A. C., Lam, J., et al. (2003). Compound heterozygosity for mutations (W156X and R225W) in SCN5A associated with severe cardiac conduction disturbances and degenerative changes in the conduction system. Circulation Research, 92(2), 159-168.

26. Smits, J. P., Koopmann, T. T., Wilders, R., Veldkamp, M. W., Opthof, T., Bhuiyan, Z. A., et al. (2005). A mutation in the human cardiac sodium channel (E161K) contributes to sick sinus syndrome, conduction disease and Brugada syndrome in two families. Journal of Molecular and Cellular Cardiology, 38(6), 969-981.

27. Makita, N., Sasaki, K., Groenewegen, W. A., Yokota, T., Yokoshiki, H., Murakami, T., et al. (2005). Congenital atrial standstill associated with coinheritance of a novel SCN5A mutation and connexin 40 polymorphisms. Heart Rhythm, 2(10), $1128-1134$.

28. Gui, J., Wang, T., Jones, R. P., Trump, D., Zimmer, T., \& Lei, M. (2010). Multiple loss-of-function mechanisms contribute to SCN5A-related familial sick sinus syndrome. PLoS One, 5(6), e10985.

29. Olson, T. M., Michels, V. V., Ballew, J. D., Reyna, S. P., Karst, M. L., Herron, K. J., et al. (2005). Sodium channel mutations and susceptibility to heart failure and atrial fibrillation. JAMA, 293(4), 447-454.

30. Wang, D. W., Viswanathan, P. C., Balser, J. R., George, A. L., Jr., \& Benson, D. W. (2002). Clinical, genetic, and biophysical characterization of SCN5A mutations associated with atrioventricular conduction block. Circulation, 105(3), 341-346.

31. Detta, N., Frisso, G., Limongelli, G., Marzullo, M., Calabro, R., \& Salvatore, F. (2014). Genetic analysis in a family affected by sick sinus syndrome may reduce the sudden death risk in a young aspiring competitive athlete. International Journal of Cardiology, 170(3), e63-65.

32. Rossenbacker, T., Carroll, S. J., Liu, H., Kuiperi, C., de Ravel, T. J., Devriendt, K., et al. (2004). Novel pore mutation in SCN5A manifests as a spectrum of phenotypes ranging from atrial flutter, conduction disease, and Brugada syndrome to sudden cardiac death. Heart Rhythm, 1(5), 610-615.

33. Horne, A. J., Eldstrom, J., Sanatani, S., \& Fedida, D. (2011). A novel mechanism for LQT3 with 2:1 block: a pore-lining mutation in Nav1.5 significantly affects voltage-dependence of activation. Heart Rhythm, 8(5), 770-777.

34. Viswanathan, P. C., Benson, D. W., \& Balser, J. R. (2003). A common SCN5A polymorphism modulates the biophysical effects of an SCN5A mutation. The Journal of Clinical Investigation, 111(3), 341-346.

35. Tan, H. L., Bink-Boelkens, M. T., Bezzina, C. R., Viswanathan, P. C., Beaufort-Krol, G. C., van Tintelen, P. J., et al. (2001). A sodium-channel mutation causes isolated cardiac conduction disease. Nature, 409(6823), 1043-1047.

36. Zhang, Y., Wang, T., Ma, A., Zhou, X., Gui, J., Wan, H., et al. (2008). Correlations between clinical and physiological consequences of the novel mutation R878C in a highly conserved pore residue in the cardiac $\mathrm{Na}^{+}$channel. Acta Physiologica (Oxford, England), 194(4), 311-323.

37. Ge, J., Sun, A., Paajanen, V., Wang, S., Su, C., Yang, Z., et al. (2008). Molecular and clinical characterization of a novel SCN5A mutation associated with atrioventricular block and dilated cardiomyopathy. Circulation. Arrhythmia and Electrophysiology, 1(2), 83-92. 
38. Kyndt, F., Probst, V., Potet, F., Demolombe, S., Chevallier, J. C., Baro, I., et al. (2001). Novel SCN5A mutation leading either to isolated cardiac conduction defect or Brugada syndrome in a large French family. Circulation, 104(25), 3081-3086.

39. Niu, D. M., Hwang, B., Hwang, H. W., Wang, N. H., Wu, J. Y., Lee, P. C., et al. (2006). A common SCN5A polymorphism attenuates a severe cardiac phenotype caused by a nonsense SCN5A mutation in a Chinese family with an inherited cardiac conduction defect. Journal of Medical Genetics, 43(10), 817-821.

40. Zumhagen, S., Veldkamp, M. W., Stallmeyer, B., Baartscheer, A., Eckardt, L., Paul, M., et al. (2013). A heterozygous deletion mutation in the cardiac sodium channel gene SCN5A with loss- and gain-of-function characteristics manifests as isolated conduction disease, without signs of Brugada or long QT syndrome. PLoS One, 8(6), e67963.

41. Grant, A. O., Carboni, M. P., Neplioueva, V., Starmer, C. F., Memmi, M., Napolitano, C., et al. (2002). Long QT syndrome, Brugada syndrome, and conduction system disease are linked to a single sodium channel mutation. The Journal of Clinical Investigation, 110(8), 1201-1209.

42. Bennett, P. B., Yazawa, K., Makita, N., \& George, A. L., Jr. (1995). Molecular mechanism for an inherited cardiac arrhythmia. Nature, 376(6542), 683-685.

43. Keller, D. I., Acharfi, S., Delacretaz, E., Benammar, N., Rotter, M., Pfammatter, J. P., et al. (2003). A novel mutation in SCN5A, delQKP 1507-1509, causing long QT syndrome: role of Q1507 residue in sodium channel inactivation. Journal of Molecular and Cellular Cardiology, 35(12), 1513-1521.

44. Akai, J., Makita, N., Sakurada, H., Shirai, N., Ueda, K., Kitabatake, A., et al. (2000). A novel SCN5A mutation associated with idiopathic ventricular fibrillation without typical ECG findings of Brugada syndrome. FEBS Letters, 479(1-2), 29-34.

45. Chang, C. C., Acharfi, S., Wu, M. H., Chiang, F. T., Wang, J. K., Sung, T. C., et al. (2004). A novel SCN5A mutation manifests as a malignant form of long QT syndrome with perinatal onset of tachycardia/bradycardia. Cardiovascular Research, 64(2), 268278 .

46. Lupoglazoff, J. M., Cheav, T., Baroudi, G., Berthet, M., Denjoy, I., Cauchemez, B., et al. (2001). Homozygous SCN5A mutation in long-QT syndrome with functional two-to-one atrioventricular block. Circulation Research, 89(2), E16-21.

47. Wei, J., Wang, D. W., Alings, M., Fish, F., Wathen, M., Roden, D. M., et al. (1999). Congenital long-QT syndrome caused by a novel mutation in a conserved acidic domain of the cardiac $\mathrm{Na}^{+}$channel. Circulation, 99(24), 3165-3171.

48. An, R. H., Wang, X. L., Kerem, B., Benhorin, J., Medina, A., Goldmit, M., et al. (1998). Novel LQT-3 mutation affects $\mathrm{Na}^{+}$ channel activity through interactions between alpha- and beta1subunits. Circulation Research, 83(2), 141-146.

49. Veldkamp, M. W., Wilders, R., Baartscheer, A., Zegers, J. G., Bezzina, C. R., \& Wilde, A. A. (2003). Contribution of sodium channel mutations to bradycardia and sinus node dysfunction in LQT3 families. Circulation Research, 92(9), 976-983.

50. Bezzina, C., Veldkamp, M. W., van Den Berg, M. P., Postma, A. V., Rook, M. B., Viersma, J. W., et al. (1999). A single $\mathrm{Na}(+)$ channel mutation causing both long-QT and Brugada syndromes. Circulation Research, 85(12), 1206-1213.

51. Tan, B. H., Iturralde-Torres, P., Medeiros-Domingo, A., Nava, S., Tester, D. J., Valdivia, C. R., et al. (2007). A novel C-terminal truncation SCN5A mutation from a patient with sick sinus syndrome, conduction disorder and ventricular tachycardia. Cardiovascular Research, 76(3), 409-417.

52. Ziyadeh-Isleem, A., Clatot, J., Duchatelet, S., Gandjbakhch, E., Denjoy, I., Hidden-Lucet, F., et al. (2014). A truncating SCN5A mutation combined with genetic variability causes sick sinus syndrome and early atrial fibrillation. Heart Rhythm, 11(6), 1015-1023.

53. Schott, J. J., Alshinawi, C., Kyndt, F., Probst, V., Hoorntje, T. M., Hulsbeek, M., et al. (1999). Cardiac conduction defects associate with mutations in SCN5A. Nature Genetics, 23(1), 20-21.

54. Probst, V., Kyndt, F., Potet, F., Trochu, J. N., Mialet, G., Demolombe, S., et al. (2003). Haploinsufficiency in combination with aging causes SCN5A-linked hereditary Lenegre disease. Journal of the American College of Cardiology, 41(4), 643-652.

55. Herfst, L. J., Potet, F., Bezzina, C. R., Groenewegen, W. A., Le Marec, H., Hoorntje, T. M., et al. (2003). $\mathrm{Na}^{+}$channel mutation leading to loss of function and non-progressive cardiac conduction defects. Journal of Molecular and Cellular Cardiology, 35(5), 549-557.

56. Lei, M., Huang, C. L., \& Zhang, Y. (2008). Genetic $\mathrm{Na}^{+}$channelopathies and sinus node dysfunction. Progress in Biophysics and Molecular Biology, 98(2-3), 171-178.

57. Butters, T. D., Aslanidi, O. V., Inada, S., Boyett, M. R., Hancox, J. C., Lei, M., et al. (2010). Mechanistic links between $\mathrm{Na}^{+}$channel (SCN5A) mutations and impaired cardiac pacemaking in sick sinus syndrome. Circulation Research, 107(1), 126-137.

58. Baruscotti, M., Westenbroek, R., Catterall, W. A., DiFrancesco, D., \& Robinson, R. B. (1997). The newborn rabbit sino-atrial node expresses a neuronal type I-like $\mathrm{Na}^{+}$channel. The Journal of Physiology, 498(Pt 3), 641-648.

59. Baruscotti, M., DiFrancesco, D., \& Robinson, R. B. (2000). Na(+) current contribution to the diastolic depolarization in newborn rabbit SA node cells. American Journal of Physiology - Heart and Circulatory Physiology, 279(5), H2303-2309.

60. Haufe, V., Cordeiro, J. M., Zimmer, T., Wu, Y. S., Schiccitano, S., Benndorf, K., et al. (2005). Contribution of neuronal sodium channels to the cardiac fast sodium current $\mathrm{INa}$ is greater in dog heart Purkinje fibers than in ventricles. Cardiovascular Research, 65(1), 117-127.

61. Du, Y., Huang, X., Wang, T., Han, K., Zhang, J., Xi, Y., et al. (2007). Downregulation of neuronal sodium channel subunits Nav1.1 and Nav1.6 in the sinoatrial node from volumeoverloaded heart failure rat. Pflügers Archiv, 454(3), 451-459.

62. Marionneau, C., Couette, B., Liu, J., Li, H., Mangoni, M. E., Nargeot, J., et al. (2005). Specific pattern of ionic channel gene expression associated with pacemaker activity in the mouse heart. The Journal of Physiology, 562(Pt 1), 223-234.

63. Greener, I. D., Monfredi, O., Inada, S., Chandler, N. J., Tellez, J. O., Atkinson, A., et al. (2011). Molecular architecture of the human specialised atrioventricular conduction axis. Journal of Molecular and Cellular Cardiology, 50(4), 642-651.

64. Kalume, F., Westenbroek, R. E., Cheah, C. S., Yu, F. H., Oakley, J. C., Scheuer, T., et al. (2013). Sudden unexpected death in a mouse model of Dravet syndrome. The Journal of Clinical Investigation, 123(4), 1798-1808.

65. Sanders, P., Kistler, P. M., Morton, J. B., Spence, S. J., \& Kalman, J. M. (2004). Remodeling of sinus node function in patients with congestive heart failure: reduction in sinus node reserve. Circulation, 110(8), 897-903.

66. Watanabe, H., Koopmann, T. T., Le Scouarnec, S., Yang, T., Ingram, C. R., Schott, J. J., et al. (2008). Sodium channel betal subunit mutations associated with Brugada syndrome and cardiac conduction disease in humans. The Journal of Clinical Investigation, 118(6), 2260-2268.

67. Lopez-Santiago, L. F., Meadows, L. S., Ernst, S. J., Chen, C., Malhotra, J. D., McEwen, D. P., et al. (2007). Sodium channel Scn 1 b null mice exhibit prolonged QT and RR intervals. Journal of Molecular and Cellular Cardiology, 43(5), 636-647.

68. Verkerk, A. O., Wilders, R., van Borren, M. M., Peters, R. J., Broekhuis, E., Lam, K., et al. (2007). Pacemaker current (I(f)) in 
the human sinoatrial node. European Heart Journal, 28(20), 2472-2478.

69. Milano, A., Vermeer, A. M., Lodder, E. M., Barc, J., Verkerk, A. O., Postma, A. V., et al. (2014). HCN4 mutations in multiple families with bradycardia and left ventricular noncompaction cardiomyopathy. Journal of the American College of Cardiology, 64(8), 745-756.

70. Nof, E., Luria, D., Brass, D., Marek, D., Lahat, H., Reznik-Wolf, H., et al. (2007). Point mutation in the HCN4 cardiac ion channel pore affecting synthesis, trafficking, and functional expression is associated with familial asymptomatic sinus bradycardia. Circulation, 116(5), 463-470.

71. Schweizer, P. A., Schroter, J., Greiner, S., Haas, J., Yampolsky, P., Mereles, D., et al. (2014). The symptom complex of familial sinus node dysfunction and myocardial noncompaction is associated with mutations in the HCN4 channel. Journal of the American College of Cardiology, 64(8), 757-767.

72. Laish-Farkash, A., Glikson, M., Brass, D., Marek-Yagel, D., Pras, E., Dascal, N., et al. (2010). A novel mutation in the HCN4 gene causes symptomatic sinus bradycardia in Moroccan Jews. Journal of Cardiovascular Electrophysiology, 21(12), 1365-1372.

73. Duhme, N., Schweizer, P. A., Thomas, D., Becker, R., Schroter, J., Barends, T. R., et al. (2013). Altered HCN4 channel C-linker interaction is associated with familial tachycardia-bradycardia syndrome and atrial fibrillation. European Heart Journal, 34(35), 2768-2775.

74. Ueda, K., Nakamura, K., Hayashi, T., Inagaki, N., Takahashi, M., Arimura, T., et al. (2004). Functional characterization of a trafficking-defective HCN4 mutation, D553N, associated with cardiac arrhythmia. The Journal of Biological Chemistry, 279(26), 27194-27198.

75. Schulze-Bahr, E., Neu, A., Friederich, P., Kaupp, U. B., Breithardt, G., Pongs, O., et al. (2003). Pacemaker channel dysfunction in a patient with sinus node disease. The Journal of Clinical Investigation, 111(10), 1537-1545.

76. Milanesi, R., Baruscotti, M., Gnecchi-Ruscone, T., \& DiFrancesco, D. (2006). Familial sinus bradycardia associated with a mutation in the cardiac pacemaker channel. The New England Journal of Medicine, 354(2), 151-157.

77. Schweizer, P. A., Duhme, N., Thomas, D., Becker, R., Zehelein, J., Draguhn, A., et al. (2010). cAMP sensitivity of HCN pacemaker channels determines basal heart rate but is not critical for autonomic rate control. Circulation. Arrhythmia and Electrophysiology, 3(5), 542-552.

78. Baruscotti, M., Bucchi, A., Viscomi, C., Mandelli, G., Consalez, G., Gnecchi-Rusconi, T., et al. (2011). Deep bradycardia and heart block caused by inducible cardiac-specific knockout of the pacemaker channel gene Hcn4. Proceedings of the National Academy of Sciences of the United States of America, 108(4), 1705-1710.

79. Perez-Lugones, A., McMahon, J. T., Ratliff, N. B., Saliba, W. I., Schweikert, R. A., Marrouche, N. F., et al. (2003). Evidence of specialized conduction cells in human pulmonary veins of patients with atrial fibrillation. Journal of Cardiovascular Electrophysiology, 14(8), 803-809.

80. Suenari, K., Cheng, C. C., Chen, Y. C., Lin, Y. K., Nakano, Y., Kihara, Y., et al. (2012). Effects of ivabradine on the pulmonary vein electrical activity and modulation of pacemaker currents and calcium homeostasis. Journal of Cardiovascular Electrophysiology, 23(2), 200-206.

81. Mangoni, M. E., \& Nargeot, J. (2008). Genesis and regulation of the heart automaticity. Physiological Reviews, 88(3), 919-982.

82. Christel, C. J., Cardona, N., Mesirca, P., Herrmann, S., Hofmann, F., Striessnig, J., et al. (2012). Distinct localization and modulation of Cav1.2 and Cav1.3 L-type $\mathrm{Ca}^{2+}$ channels in mouse sinoatrial node. The Journal of Physiology, 590(Pt 24), 6327-6342.
83. Mangoni, M. E., Traboulsie, A., Leoni, A. L., Couette, B., Marger, L., Le Quang, K., et al. (2006). Bradycardia and slowing of the atrioventricular conduction in mice lacking CaV3.1/alpha1G Ttype calcium channels. Circulation Research, 98(11), 1422-1430.

84. Strandberg, L. S., Cui, X., Rath, A., Liu, J., Silverman, E. D., Liu, X., et al. (2013). Congenital heart block maternal sera autoantibodies target an extracellular epitope on the alpha1G T-type calcium channel in human fetal hearts. PLoS One, 8(9), e72668.

85. Hu, K., Qu, Y., Yue, Y., \& Boutjdir, M. (2004). Functional basis of sinus bradycardia in congenital heart block. Circulation Research, 94(4), e32-38.

86. Baig, S. M., Koschak, A., Lieb, A., Gebhart, M., Dafinger, C., Nurnberg, G., et al. (2011). Loss of Ca(v)1.3 (CACNA1D) function in a human channelopathy with bradycardia and congenital deafness. Nature Neuroscience, 14(1), 77-84.

87. Platzer, J., Engel, J., Schrott-Fischer, A., Stephan, K., Bova, S., Chen, H., et al. (2000). Congenital deafness and sinoatrial node dysfunction in mice lacking class D L-type $\mathrm{Ca}^{2+}$ channels. Cell, 102(1), 89-97.

88. Mangoni, M. E., Couette, B., Bourinet, E., Platzer, J., Reimer, D., Striessnig, J., et al. (2003). Functional role of L-type Cav1.3 $\mathrm{Ca}^{2+}$ channels in cardiac pacemaker activity. Proceedings of the National Academy of Sciences of the United States of America, 100(9), 5543-5548.

89. Lahat, H., Eldar, M., Levy-Nissenbaum, E., Bahan, T., Friedman, E., Khoury, A., et al. (2001). Autosomal recessive catecholamineor exercise-induced polymorphic ventricular tachycardia: clinical features and assignment of the disease gene to chromosome 1p1321. Circulation, 103(23), 2822-2827.

90. Sumitomo, N., Sakurada, H., Taniguchi, K., Matsumura, M., Abe, O., Miyashita, M., et al. (2007). Association of atrial arrhythmia and sinus node dysfunction in patients with catecholaminergic polymorphic ventricular tachycardia. Circulation Journal, 71(10), 1606-1609.

91. Gao, Z., Rasmussen, T. P., Li, Y., Kutschke, W., Koval, O. M., $\mathrm{Wu}$, Y., et al. (2013). Genetic inhibition of $\mathrm{Na}^{+}-\mathrm{Ca}^{2+}$ exchanger current disables fight or flight sinoatrial node activity without affecting resting heart rate. Circulation Research, 112(2), 309-317.

92. Groenke, S., Larson, E. D., Alber, S., Zhang, R., Lamp, S. T., Ren, X., et al. (2013). Complete atrial-specific knockout of sodiumcalcium exchange eliminates sinoatrial node pacemaker activity. PLoS One, 8(11), e81633.

93. Simrick, S., Schindler, R. F., Poon, K. L., \& Brand, T. (2013). Popeye domain-containing proteins and stress-mediated modulation of cardiac pacemaking. Trends in Cardiovascular Medicine, 23(7), 257-263.

94. Froese, A., Breher, S. S., Waldeyer, C., Schindler, R. F., Nikolaev, V. O., Rinne, S., et al. (2012). Popeye domain containing proteins are essential for stress-mediated modulation of cardiac pacemaking in mice. The Journal of Clinical Investigation, 122(3), 1119-1130.

95. Kirchmaier, B. C., Poon, K. L., Schwerte, T., Huisken, J., Winkler, C., Jungblut, B., et al. (2012). The Popeye domain containing 2 (popdc2) gene in zebrafish is required for heart and skeletal muscle development. Developmental Biology, 363(2), 438-450.

96. Szûts, V., Ötvös, F., Dézsi, L., Vágvölgyi, C., Szalontai, B., Dobrzynski, H., et al. (2012). What have we learned from twopore potassium channels? Their molecular configuration and function in the human heart. Acta Biologica Szegediensis, 56(2), 93-107.

97. Yanni, J., Tellez, J. O., Maczewski, M., Mackiewicz, U., Beresewicz, A., Billeter, R., et al. (2011). Changes in ion channel gene expression underlying heart failure-induced sinoatrial node dysfunction. Circulation. Heart Failure, 4(4), 496-508.

98. Lalevee, N., Monier, B., Senatore, S., Perrin, L., \& Semeriva, M. (2006). Control of cardiac rhythm by ORK1, a Drosophila twopore domain potassium channel. Current Biology, 16(15), 15021508 . 
99. Schindler, R. F., Poon, K. L., Simrick, S., \& Brand, T. (2012). The Popeye domain containing genes: essential elements in heart rate control. Cardiovasc Diagn Ther, 2(4), 308-319.

100. Brand, T., Simrick, S. L., Poon, K. L., \& Schindler, R. F. (2014). The cAMP-binding Popdc proteins have a redundant function in the heart. Biochemical Society Transactions, 42(2), 295-301.

101. Camozzi, D., Capanni, C., Cenni, V., Mattioli, E., Columbaro, M., Squarzoni, S., et al. (2014). Diverse lamin-dependent mechanisms interact to control chromatin dynamics: focus on laminopathies. Nucleus, 5(5).

102. Mohler, P. J., \& Bennett, V. (2005). Ankyrin-based cardiac arrhythmias: a new class of channelopathies due to loss of cellular targeting. Current Opinion in Cardiology, 20(3), 189-193.

103. Robaei, D., Ford, T., \& Ooi, S. Y. (2014). Ankyrin-b syndrome: a case of sinus node dysfunction, atrial fibrillation and prolonged QT in a young adult. Heart Lung Circulatory

104. Mohler, P. J., Le Scouarnec, S., Denjoy, I., Lowe, J. S., Guicheney, P., Caron, L., et al. (2007). Defining the cellular phenotype of "ankyrin-B syndrome" variants: human ANK2 variants associated with clinical phenotypes display a spectrum of activities in cardiomyocytes. Circulation, 115(4), 432-441.

105. Ackerman, M. J., \& Mohler, P. J. (2010). Defining a new paradigm for human arrhythmia syndromes: phenotypic manifestations of gene mutations in ion channel- and transporter-associated proteins. Circulation Research, 107(4), 457-465.

106. Barbuti, A., Terragni, B., Brioschi, C., \& DiFrancesco, D. (2007). Localization of $\mathrm{f}$-channels to caveolae mediates specific beta2adrenergic receptor modulation of rate in sinoatrial myocytes. Journal of Molecular and Cellular Cardiology, 42(1), 71-78.

107. Vatta, M., Ackerman, M. J., Ye, B., Makielski, J. C., Ughanze, E. E., Taylor, E. W., et al. (2006). Mutant caveolin-3 induces persistent late sodium current and is associated with long-QT syndrome. Circulation, 114(20), 2104-2112.

108. Cronk, L. B., Ye, B., Kaku, T., Tester, D. J., Vatta, M., Makielski, J. C., et al. (2007). Novel mechanism for sudden infant death syndrome: persistent late sodium current secondary to mutations in caveolin-3. Heart Rhythm, 4(2), 161-166.

109. Barbuti, A., Scavone, A., Mazzocchi, N., Terragni, B., Baruscotti, M., \& Difrancesco, D. (2012). A caveolin-binding domain in the $\mathrm{HCN} 4$ channels mediates functional interaction with caveolin proteins. Journal of Molecular and Cellular Cardiology, 53(2), 187195.

110. Liu, Y., Bai, R., Wang, L., Zhang, C., Zhao, R., Wan, D., et al. (2013). Identification of a novel de novo mutation associated with PRKAG2 cardiac syndrome and early onset of heart failure. PLoS One, 8(5), e64603. 